\title{
Case report: dermoscopic and histological aspects of skin graft and perigraft hyperpigmentation in acral location*
}

\author{
Bruna Tuma ${ }^{1}$ \\ Rodrigo Almeida de Medeiros ${ }^{3}$ \\ Sergio Henrique Hirata $^{2}$
}

\author{
Sergio Yamada ${ }^{2}$ \\ Mauricio Mendonca do Nascimento ${ }^{2}$
}

DOI: http://dx.doi.org/10.1590/abd1806-4841.20142709

\begin{abstract}
Little is known about the use of dermoscopy in skin grafting. We describe the case of a patient with skin grafting and surrounding pigmentation on acral region. The dermoscopic findings were similar to those of benign acral lesions (lattice-like pattern) and reactive pigmentations (fine striae). Histopathology revealed pigment leakage and increased number of melanocytes. It is believed that this phenomenon occured as the result of an inflammatory stimulus.
\end{abstract}

Keywords: Dermoscopy; Hand Injuries; Skin Transplantation

\section{INTRODUCTION}

Dermoscopy is a valuable instrument in dermatological examination, a non-invasive technique that helps distinguish between benign and malignant melanocytic lesions by identifying morphological structures not visible to the naked eye. The test is particularly useful in the acral region where it is simple, easy to interpret and particularly important because this is the most frequent area of melanoma in non-Caucasians. ${ }^{1}$

Skin grafting is a surgical technique widely used to correct tissue loss, but little is known about the graft behavior and its dermoscopic features. ${ }^{2}$ We describe a case of graft and perilesional area hyperpigmentation in a patient submitted to skin grafting on the second right finger. We discuss the dermoscopic and histopathological aspects of this phenomenon.

\section{CASE REPORT}

Sixty-nine year-old male, farm worker with skin type VI, reported an episode of trauma in the second finger of the right hand 34 years ago when he was submitted to total skin graft, having the chest as the donor area. The patient did not recall when hyperpigmentation in the perigraft area first started.

On examination, we identified a black plaque with hair growth associated with a peripheral brown macule (Figure 1). The plaque corresponded to the graft

Received on 22.04.2013.

Approved by the Advisory Board and accepted for publication on 17.07.2013.

* Work performed at a private practice in Londrina- PR, Brazil.

Conflict of interest: None

Financial funding: None

Universidade Estadual de Londrina (UEL) - Londrina (PR), Brazil.

Universidade Federal de São Paulo (Unifesp) - São Paulo (SP), Brazil

Private practice - Londrina (PR), Brazil.

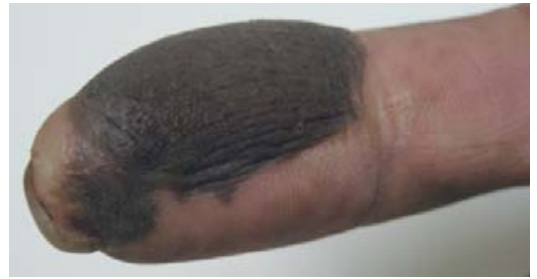

Figure 1:

Clinical aspect of the lesion. Clinical photography of the second right finger skin graft

itself, and the macule, to the area around the graft. At dermoscopy, the graft area presented homogeneous pigmentation, and the macular perigraft area had a latticelike pattern (Figures 2 and 3). The area of graft insertion presented a hypochromic scar region, fine striae perpendicular to the scar and dots / globules (Figure 4).

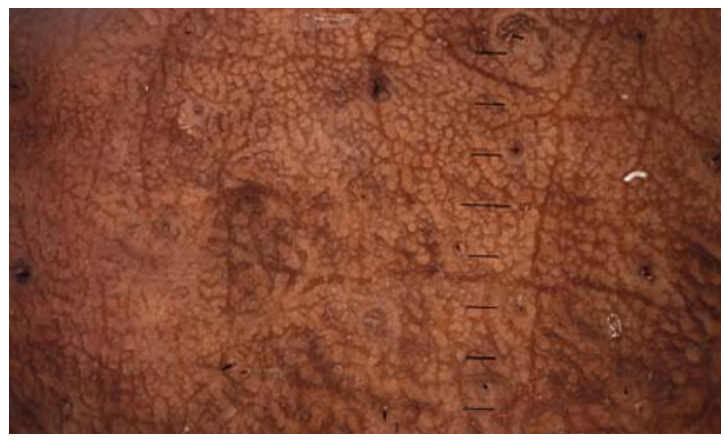

Figure 2: Dermoscopic exam of the graft. Dermoscopic photography of the graft 


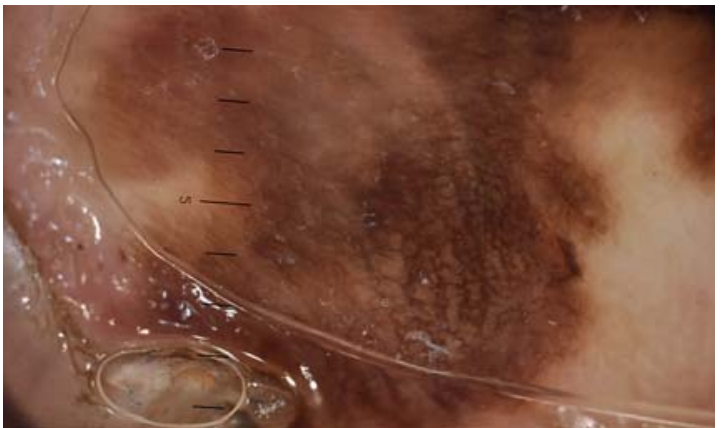

FiguRE 3: Dermoscopy of perigraft macule

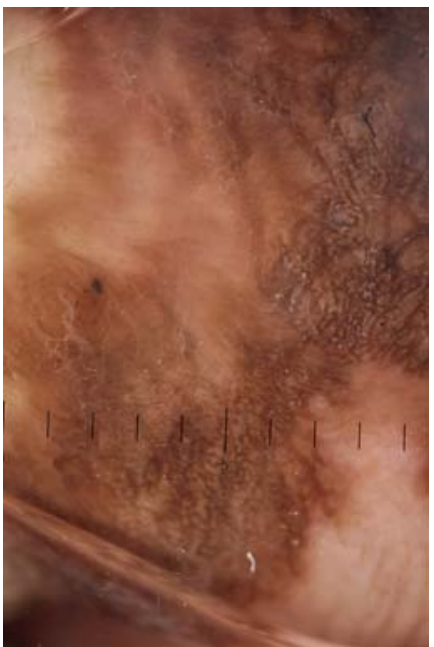

Figure 4:

Dermoscopy of the transitional area. Dermoscopic photography of the transitional area between the graft and the perigraft macule
We performed a biopsy in the graft-hyperpigmentation transitional area and in the perigraft hyperpigmentation area, following the algorithm proposed by Saida et al. ${ }^{3,4}$ Two other areas were biopsied for academic purposes and with the patient's informed consent: the normal acral skin and the graft itself.

In the grafted area, histopathological examination showed hyperorthokeratosis in basket weave (a pattern also found, although more tenuously, in the normal acral skin), acanthosis, papillomatosis, and melanic epidermal hyperpigmentation mostly visible on the tips of epidermal ridges and pigmentary incontinence (Figure 5).

In the hyperpigmentation area surrounding the graft, the biopsy revealed the same histopathological features found on the graft area, with a higher number of melanocytes, less melanic hyperpigmentation and pigmentary incontinence (Figure 6). Added to these characteristics, the graft insertion area showed fibrosis in the superficial dermis.

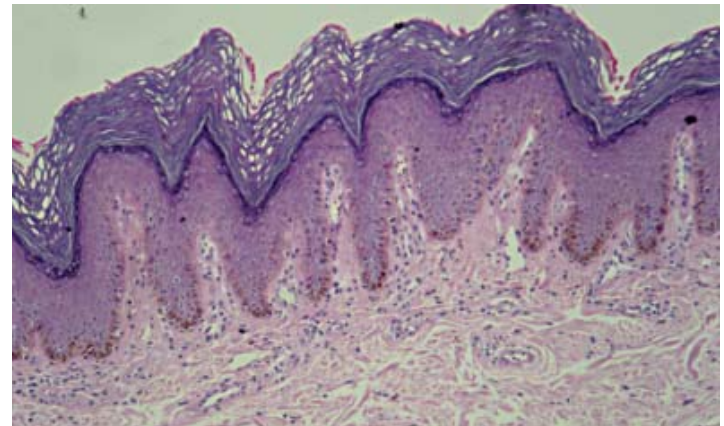

FIGURE 5: Anatomopathological exam of graft fragment. HE stain. 10X magnification. Presence of hyperorthokeratosis in basket weave (more tenuous than normal skin). Note epidermic melanic hyperpigmentation and pigment leakage in moderate quantity

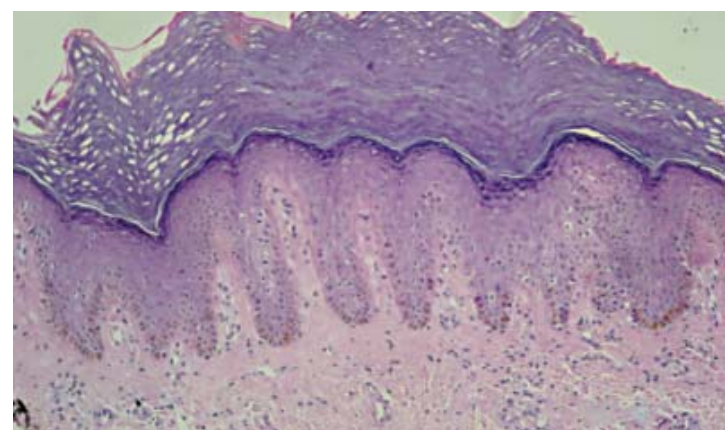

FIGURE 6: Anatomopathological exam of adjacent hypermelanosis area. HE stain. 10X magnification. Hyperorthokeratosis in basket weave (more tenuous than normal skin). Presence of epidermic melanic hyperpigmentation mainly at the tips of epidermic ridges and pigment leakage in small quantity. Increased melanocyte count

\section{DISCUSSION}

The evolution and clinical aspects of skin grafts are rarely discussed in the literature. In clinical practice, it is observed that the skin grafts acquire, over the years, the phenotypic aspects of the receiving region.

In this case report, we observed that the graft had aspects both of glabrous skin represented by the presence of hair growth and active melanocytes, as well as acral skin, illustrated by the hyperorthokeratosis in basket weave and the melanin distribution pattern. Regarding the melanocyte counting, we noted that the number of melanocytes was greater in the grafted area and hyperpigmented macule than in the normal acral skin (Table 1).

A recent study demonstrated that fibroblasts stimulate dopamine oxidase activity in melanocytes, which would be one of the explanations for the periscar pigmentation. ${ }^{5}$ The authors believe that the increased number of melanocytes in the region around the graft is due to two mechanisms, post- 
Table 1: Correlation between observed area and histopathological findings

\begin{tabular}{llll}
\hline Histopathological aspects & Normal skin (acral) & Graft & Perigraft macule \\
\hline Melanocyte counting/ 2mm & 19 & 47 & 56 \\
Melanin distribution & Absent & Epidermic, 2+ & Epidermic, 1+ \\
Pigmentary incontinence & Absent & $2+$ & $1+$ \\
\hline
\end{tabular}

inflammatory and melanocyte migration from the graft.

From the dermoscopic point of view, homogeneous black pigmentation in the graft can be justified by epidermal hyperpigmentation and pigment leakage, and the increase in pigmentation in the furrows can be explained by the predominant location of melanin in epidermal ridges. ${ }^{6,7}$

In the graft-acral skin transitional area we identified hypochromic scarring, justified by the insertion of the graft in the acral skin, fine and homogeneous striae and some spots. According to the study by Botella-Estrada et al. the presence of fine and homogeneous striae is associated with reactive pigmentation $(\mathrm{p}=0.026)$, and the spots with lesion recurrence $(\mathrm{p}$ $<0.0001) .{ }^{8}$ Applying the latter concept to the present case, the predominant structures are the striae and because it is not a case of melanocytic tumor excision scar we can not affirm that this is a reactive pigmentation or de novo melanocytic proliferation event, which justifies the regional biopsy. ${ }^{9}$

\section{REFERENCES}

1. Ishihara K, Saida T, Yamamoto A; Japanese Skin Cancer Society Prognosis and Statistical Investigation Committee. Updated statistical data for malignant melanomain Japan. Int J Clin Oncol. 2001;6:109-16.

2. Shimizuand R, Kishi K; Review Article: Skin Grafts. Plast Surg Int. 2012; 563493: 1-5.

3. Saida T, Koga H. Dermoscopic Patterns of Acral Melanocytic Nevi Their Variations, Changes, and Significance. Arch Dermatol. 2007;143:1423-6.

4. Koga H, Saida T. Revised 3-Step Dermoscopic Algorithm for the Management of Acral Melanocytic Lesions. Arch Dermatol. 2011:147:741-3.

5. Hedley SJ, Layton C, Heaton M, Chakrabarty KH, Dawson RA, Gawkrodger DJ, et al. Fibroblasts play a regulatory role in the control of pigmentation in reconstructed human skin from skin types I and II. Pigment Cell Res. 2002;15:49-56.

6. Kimoto M, Sakamoto M, Iyatomi H, Tanaka M. Three-Dimensional Melanin Distribution of Acral Melanocytic Nevi Is Reflected in Dermoscopy Features: Analysis of the Parallel Pattern. Dermatology. 2008:216:205-12.

7. Miyazaki A, Saida T, Koga H, Oguchi S, Suzuki T, Tsuchida T. Anatomical and histopathological correlates of the dermoscopic patterns seen in melanocytic nevi on the sole: A retrospective study. J Am Acad Dermatol. 2005;53:230-6.

8. Botella-Estrada R, Nagore E, Sopena J, Cremades A, Alfaro A, Sanmartín O, et al. Clinical, dermoscopy and histological correlation study of melanotic pigmentations in excision scars of melanocytic tumours. Br J Dermatol. 2006;154:478-84.

9. Saida $\mathrm{T}$, Koga $\mathrm{H}$, Uhara H. Key points in dermoscopic differentiation between early acral melanoma and acral nevus. J Dermatol. 2011;38:25-34.

10. Maia M, Lellis RF, Marta AC. Ex vivo dermoscopy: synchronic evaluation between dermatologist and dermatopathologist of melanocytic lesions. An Bras Dermatol. 2009;84:553-5.
The region corresponding to the macule around the graft shows a similar dermoscopic pattern to that found in benign melanocytic lesions, a lattice-like pattern. ${ }^{7}$ Dermoscopy of acral region visualizes melanin granules arranged in columns in the stratum corneum; so benign pigmented lesions in this anatomical area may mimic melanocytic nevi. ${ }^{6}$

In the case reported here, dermoscopy was critical to discuss diagnostic hypotheses for this phenomenon, indicate the best approach, and to guide the biopsy, improving the histopathological examination

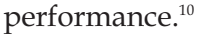

Despite numerous articles on dermoscopy, little is known about the use of this technique in skin grafts. Here, we could glimpse at a new use of dermoscopy; however, studies that include more patients are still necessary. Then, we could define clinical and dermoscopic patterns of skin graft pigmentation and know when we are facing a high-risk lesion. $\square$

How to cite this article: Tuma B, Yamada S Medeiros RA, Nascimento MM, Hirata SH. Case report: dermoscopic and histological aspects of skin graft and perigraft hyperpigmentation in acral location. An Bras Dermatol. 2014;89(3):510-2. 